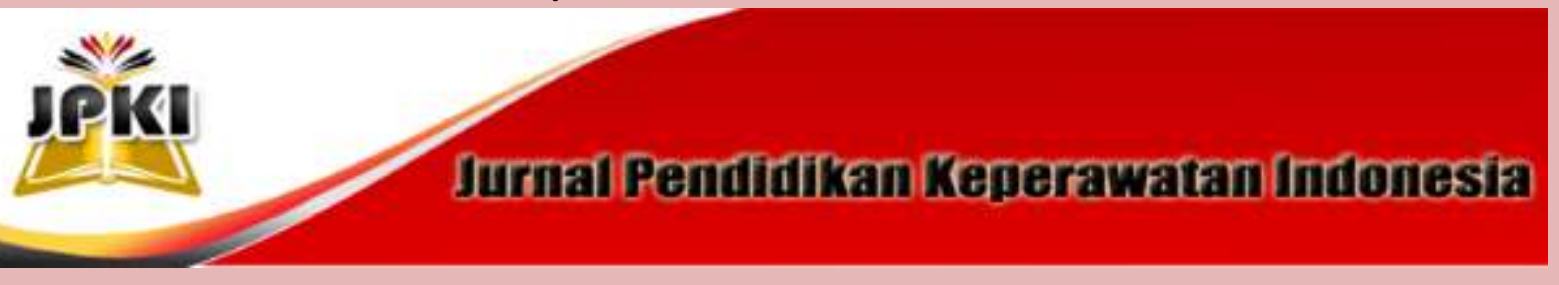

Journal homepage : http://ejournal.upi.edu/index.php/JPKI

\title{
GAMBARAN PENGETAHUAN LANSIA MENGENAI SENAM LANSIA DI PANTI SOSIAL TRESNA WERDHA BUDI PERTIWI
}

\author{
${ }^{1}$ Upik Rahmi, ${ }^{2}$ Budi Somantri, ${ }^{3}$ Nisa Yusrina Nur Alifah \\ ${ }^{1,2,3}$ Prodi D3 Keperawatan FPOK Universitas Pendidikan Indonesia \\ Email : upikrahmi@upi.edu
}

\begin{abstract}
ABSTRAK
Di Indonesia proporsi penduduk berusia lanjut terus membesar. Indonesia termasuk lima besar negara dengan jumlah penduduk lanjut usia terbanyak di dunia yakni mencapai 18,1 juta jiwa pada 2010. Dengan bertambahnya jumlah penduduk dan usia harapan hidup lansia akan menimbulkan berbagai masalah antara lain masalah kesehatan, psikologi dan sosial ekonomi. Salah satu permasalahan pada lansia adalah penurunan aktivitas akibat proses penuaan ditandai dengan kurangnya motivasi lansia mengikuti senam lansia. Hal ini dikarena kurangnya pengetahuan lansia mengenai senam lansia. Adapun tujuan dari penelitian ini adalah untuk mengidentifikasi gambaran pengetahuan lansia mengenai senam lansia. Penelitian ini menggunakan metode deksriptif kuantitatif, dengan teknik pengambilan data sampel menggunakan total sampling. Jumlah responden yang di ambil sebanyak 29 lansia di panti sosial tresna werdha budi pertiwi. Intrument menggunakan kuisoner dan teknik analisa data menggunakan distribusi frekuensi. Hasil penelitian menunjukan bahwa distribusi frekuensi responden berdasarkan usia $60-74$ tahun $(48,3 \%)$ atau lebih dari sebagian besar lansia berpengetahuan baik 14 lansia (48,3\%), dan lansia yang berpengetahuan cukup 14 lansia $(48,3 \%)$ dan berpengetahuan kurang ada 1 lansia $(3,4 \%)$. Dari hasil penelitian ini dapat disimpulkan bahwa hampir setengahnya $(48,3 \%)$ berpengetahuan baik dan cukup. Adapun saran bagi tenaga kesehatan adalah diadakannya penyuluhan tentang senam lansia.
\end{abstract}

Kata Kunci : Pengetahuan, Senam Lansia, Lansia

\begin{abstract}
In Indonesia, the proportion of the elderly population continues to grow. Indonesia is among the top five countries with the highest number of elderly people in the world, reaching 18.1 million in 2010. The increasing of population and life expectancy of the elderly will cause various problems among other health problems, psychological and socio-economic. One of the problems in the elderly is a decrease in activity due to aging is characterized by a lack of motivation to follow gymnastics elderly. This is caused by a lack of knowledge about gymnastics elderly. The purpose of this study was to identify the description of the elderly knowledge about gymnastics. This research is using quantitative descriptive method, with sample data retrieval technique using total sampling. The number of respondents who took as many as 29 elderly people in social institutions Tresna Werdhana Budi Pertiwi. Instrument using questionnaires and data analysis techniques using frequency distribution. The results of the research showed that the frequency distribution of respondents by age 60-74 years (48.3\%) or more of the mostly elderly knowledgeable both 14 elderly (48.3\%), and the elderly who are knowledgeable enough 14 elderly (48.3\%) and No less knowledgeable one elderly (3.4\%). From these results it can be concluded that nearly half (48.3\%) and fairly good knowledge. As for advice for health workers is holding counseling about gymnastics elderly.
\end{abstract}

Keywords: Knowledge, Gymnastics Elderly, Elderly 


\section{PENDAHULUAN}

Lanjut usia merupakan salah satu fase hidup yang akan dialami oleh setiap manusia, meskipun usia bertambah dengan diiringi penurunan fungsi organ tubuh tetapi lansia tetap dapat menjalani hidup sehat. Salah satu hal yang paling penting adalah merubah kebiasaan. Tidak hanya meninggalkan kebiasaan buruk yang dapat mengganggu kesehatan, tetapi beberapa pola hidup sehat seperti olah raga dan menjaga pola makan memang harus dilaksanakan (PKPU Lembaga Kemanusiaan Nasional, 2011).

Menurut organisasi kesehatan dunia, WHO (World Health Organization) seseorang disebut lanjut usia (elderly) jika berumur 60-74 tahun. Berdasarkan pengertian lanjut usia secara umum, seseorang dikatakan lanjut usia (lansia) apabila usianya 65 tahun keatas (Effendi dan Makhfudli, 2009). Menurut WHO batasan lanjut usia meliputi usia pertengahan (middle age), yaitu kelompok usia 45 sampai 59 tahun, lanjut usia (elderly), antara 60 sampai 74 tahun, lanjut usia tua (old), antara 75 sampai 90 tahun, usia sangat tua (very old), diatas 90 tahun.

$$
\text { Proporsi lansia di dunia }
$$

diperkirakan mencapai 22 persen dari penduduk dunia atau sekitar 2 miliar pada tahun 2020, sekitar 80\% lansia hidup di negara berkembang. Rata-rata usia harapan hidup di negara-negara kawasan Asia Tenggara adalah 70 tahun. Jumlah penduduk di 11 negara kawasan Asia Tenggara yang berusia di atas 60 tahun berjumlah 142 juta orang dan diperkirakan akan terus meningkat hingga 3 kali lipat di tahun 2050 sedangkan di Indonesia termasuk cukup tinggi yaitu 71 tahun (riskesdas, 2013).

Di Indonesia proporsi penduduk berusia lanjut terus membesar. Indonesia termasuk lima besar negara dengan jumlah penduduk lanjut usia terbanyak di dunia yakni mencapai 18,1 juta jiwa pada 2010 atau $9,6 \%$ dari jumlah penduduk (Sensus Penduduk, 2010). Jumlah lansia meningkat di seluruh Indonesia menjadi 15,1 juta jiwa pada tahun 2000 atau $7,2 \%$ dari seluruh penduduk dengan usia harapan hidup 64,05 tahun. Tahun 2006 usia harapan hidup meningkat menjadi 66,2 tahun dan jumlah lansia menjadi 19 juta orang, dan diperkirakan pada tahun 2020 akan menjadi 29 juta orang atau 11,4\% (riskesdas, 2013).

Pengetahuan (knowledge) adalah hasil tahu dari manusia, yang sekedar menjawab pertanyaan "what". Pada dasarnya pengetahuan merupakan hasil tahu dari manusia terhadap sesuatu, atau segala perbuatan dari manusia untuk memahami suatu objek tertentu. Pengetahuan dapat berwujud barangbarang baik lewat indera maupun lewat akal, dapat pula objek yang dipahami oleh manusia berbentuk ideal atau bersangkutan dengan masalah kejiwaan.

Dengan bertambahnya jumlah penduduk dan usia harapan hidup lansia akan menimbulkan berbagai masalah antara lain masalah kesehatan, psikologi dan sosial ekonomi. Sebagian besar permasalahan pada lansia adalah masalah kesehatan akibat proses penuaan ditambah dengan masalah lain seperti masalah keuangan, kesepian, merasa tidak berguna dan tidak produktif.

Kesegaran jasmani cenderung mengalami penurunan seiring dengan bertambahnya usia seseorang. Penurunan semakin terlihat setelah seseorang berusia 40 tahun dan akan menurun $30-50 \%$ pada saat usia lanjut. Salah satu faktor presdisposisi penurunan kesegaran jasmani adalah kurangnya aktivitas fisik seorang lansia biasanya akan mengalami keterbatasan dalam melakukan aktifivitas sehingga cenderung kurang beraktivitas. Terutama dalam melakukan olahraga seperti jogging, jalan sehat dan senam lansia. ( Hilda fauziah, 2012 )

Senam lansia adalah serangkaian gerak nada yang teratur dan terarah serta terencana yang diikuti oleh orang lanjut usia yang dilakukan dengan maksud meningkatkan kemampuan fungsional raga untuk mencapai tujuan tersebut. (Santosa, 2010). Dalam Indonesia Nursing (2008) 
senam lansia disamping memiliki dampak positif terhadap peningkatan fungsi organ tubuh juga berpengaruh dalam meningkatkan imunitas dalam tubuh manusia setelah latihan teratur.

Olahraga pada usia lanjut dapat dilakukan dengan memperhatikan tingkat kekuatan, seperti jalan cepat, bersepeda santai dan senam dapat dilakukan secara rutin. "Bahkan aktivitas sehari-hari seperti membersihkan rumah, berkebun dan mencuci pakaian dengan intensitas selama 30 menit juga baik bagi kesehatan. Penting bagi lansia untuk mengikuti senam karena akan membantu tubuh lansia agar tetap bugar dan tetap segar, karena senam lansia mampu melatih tulang tetap kuat, mendorong jantung bekerja secara optimal dan membantu menghilangkan radikal bebas yang terdapat didalam tubuh. Semua jenis senam dan aktivitas olahraga ringan sangat bermanfaat untuk menghambat proses degeneratif atau proses penuaan (Widianti, 2010).

Penelitian yang dilakukan oleh Warda Jamilah (2012) dari hasil penelitian ini menunjukkan tingkat pengetahuan lansia tentang senam lansia dalam kategori baik. Hal ini dapat dilihat dari hasil jawaban responden dengan kategori baik sebanyak $67,3 \%$, sedang $11,5 \%$, dan kategori sangat baik 21,1\%. Sikap Lansia dalam penelitian ini mayoritas responden dalam kategori baik yaitu sebanyak $80,7 \%$, sedangkan kategori sedang sebanyak $19,2 \%$.

$$
\text { Faktor yang mendukung }
$$

pengetahuan lansia dapat dikategorikan baik yaitu bila dilihat dari keadaan responden hal ini memungkinkan responden memiliki pengetahuan baik karena didukung oleh pengalaman dan motivasi responden yang kuat untuk tetap memperoleh informasi. Hal ini kemungkinan juga dapat berhubungan dengan pengalaman, budaya dan kesempatan untuk mendapatkan informasi yang didapatkan responden dalam kehidupannya sehari - hari. Sebagai saran penelitian selanjutnya perbandingan pengetahuan lansia terhadap motivasi melakukan senam lansia terhadap lansia yang ada di panti dengan lansia di masyarakat.

Penelitian Veronica, dkk (2011) menunjukkan bahwa tingkat pengetahuan lansia dalam kategori baik (54\%), cukup $(6 \%)$, dan kurang (40\%). Berdasakan hasil uji Spearman's Rho diketahui bahwa arah korelasi positif dan terdapat kekuatan hubungan tingkat sedang antara tingkat pengetahuan tentang senam lansia dengan keaktifan mengikuti senam lansia. Nilai koefisien korelasi sebesar 0,435 dan nilai signifikansi $\mathrm{p}=0,002(\mathrm{P}<0,05)$. Berdasarkan hasil penelitian diatas diharapkan dengan semakin baiknya tingkat pengetahuan lansia tentang senam lansia.

Didapatkan data lansia yaitu jumlah lansia pada tahun 2015 di Panti Sosial Tresna Werdha Budi pertiwi ini adalah 29 lansia. Semua lansia yang tinggal dip anti semuanya adalah lansia perempuan. Berdasarkan studi pendahuluan yang dilakukan pada tanggal 04 April 2015 dari lima lansia yang diwawancarai, semua lansia mengatakan selalu mengikuti senam lansia dua kali dalam seminggu setiap hari selasa dan rabu. Lima lansia tersebut mengatakan senam lansia yang diadakan di panti sosial hanya sebagai rutinitas yang harus dijalaninya saja. Dua diantara lima lansia kurang motivasi mengikuti kegiatan senam lansia karena lelah sedangkan tiga yang lainnya mengatakan jika sedang sakit tidak pernah mengikuti senam lansia.

Dari hasil pemaparan di atas maka peneliti tertarik untuk mengangkat judul penelitian "Gambaran pengetahuan lansia mengenai senam lansia".

\section{METODOLOGI}

Metode penelitian ini menggunakan metode deskriptif dengan pendekatan kuantitatif. Populasi dalam penelitian adalah 29 lansia di panti sosial tresna werdha budi pertiwi bandung. Sampel dalam penelitian ini 29 lansia dan 
pengambilan sampel dalam penelitian ini menggunakan teknik Total Sampling. Intrument dalam penelitian ini menggunakan kuisoner tertutup. Kuesoiner dalam penelitian ini menggunakan skala Guttman yaitu skala yang bersifat tegas dan konsisten dengan memberikan jawaban tegas seperti jawaban dari pertanyaan/pernyataan : ya dan tidak, positif dan negatif, setuju dan tidak setuju, benar dan salah. Skala Guttman ini umumnya dibuat seperti checklist dengan interpretasi penilaian, apabila skor benar nilainya 1 dan apabila salah nilainya 0 (Hidayat, 2011).

Instrumen yang digunakan dalam penelitian ini berupa kuesioner. Kuesioner adalah daftar pertanyaan yang sudah tersusun dengan baik, sudah matang, dimana responden (dalam hal kuesioner) dan interview (dalam hal wawancara) tinggal memberikan jawaban atau dengan memberikan tanda-tanda tertentu (Notoatmodjo, 2010). Adapun bentuk pernyataan yang digunakan dalam kuesioner ini adalah kuesioner berbentuk pilihan dimana jawabannya telah disediakan closed ended item.

Uji validitas instrumen ini dilakukan kepada 10 responden di Panti Sosial Tresna Werdha Senjarawi Bandung pada tanggal 18 Mei 2015 surat izin untuk uji validitas masuk dan di izinkan dari pihak Panti Sosial Tresna Werdha Senjarawi Bandung adalah tanggal 19 Mei 2015 untuk melakukan uji validitas. Dari 30 pertanyaan, 13 pertanyaan tersebut dinyatakan valid dan 17 pertanyaan tersebut tidak valid karena $r$ hasil $<0,514$. Petanyaan yang tidak valid selanjutnya diperbaiki redaksi kalimatnya kepada pembimbing, dan tetap digunakan untuk penelitian yang sebenarnya.

Pertanyaan yang sudah valid dilakukan uji reliabilitas dengan cara membandingkan $\mathrm{r}$ hasil (alpha) dengan konstanta $(0,7)$. Jika nilai $\mathrm{r}$ hasil adalah alpha yang terletak di awal output dengan tingkat kemaknaan 5\% $(0,05)$ maka setiap pertanyaan kuesioner dikatakan valid jika $\mathrm{r}$ Jurnal Pendidikan Keperawatan Indonesia 2(1) : 38-43 (2016) alpha > konstanta $(0,7)$ maka pertanyaan tersebut reliable.

Berdasarkan hasil uji reliabilitas kepada 10 orang responden di Panti Sosial Tresna Werdha Senjarawi Bandung didapatkan nilai $\mathrm{r}($ alpha $)=0,712$ sehingga diperoleh kesimpulan bahwa item pertanyaan tersebut reliabel.

Analisa data yang digunakan dalam penelitian ini adalah analisis univariat yang bertujuan untuk menjelaskan atau mendeskripsikan karakteristik setiap variabel penelitian (Notoatmodjo,2010). Analisis secara diskriptif ini nantinya menghasilkan distribusidan persentase dari setiap variabel, dan disajikan dalam bentuk narasi,tabel dan diagram. Untuk mengetahui pengetahuan Lansia Di panti social tresna werdha budi pertiwi tentang senam lansia yang diperoleh dari wawancara dengan alat bantu kuesioner. Setiap jawaban yang benar diberi nilai 1, dan jawaban yang salah diberi nilai 0 .

\section{HASIL DAN PEMBAHASAN}

\section{Distribusi frekuensi responden berdasarkan pengetahuan pada lansia mengenai senam lansia di PSTW Budi Pertiwi}

Tabel 1. Distribusi Frekuensi Responden Gambaran Pengetahuan Lansia Mengenai Senam Lansia di Panti Sosial Tresna Werdha Budi Pertiwi $(n=29)$

\begin{tabular}{lcc}
\hline Pengetahuan & f & \% \\
\hline Baik & 14 & $48,3 \%$ \\
Cukup & 14 & $48,3 \%$ \\
Kurang & 1 & $3,4 \%$ \\
Jumlah & 29 & $100 \%$ \\
\hline
\end{tabular}

Sumber : Data Primer

Berdasarkan tabel diatas dapat dilihat bahwa pengetahuan pada lansia di panti sosial tresna werdha budi pertiwi mengenai senam lansia menunjukan sebagian responden berpengetahuan baik 14 lansia $(48,3 \%)$, berpengetahuan cukup 14 lansia (48,3 \%) dan sebagian kecil responden berpengetahuan kurang 1 lansia $(3,4 \%)$. 
Tabel 2. Distribusi Frekuensi Responden Berdasarkan Usia Pada Lansia Di Panti Sosial Tresna Werdha Budi Pertiwi

\begin{tabular}{lcc}
\hline Usia (tahun) & f & \% \\
\hline $60-74$ & 14 & $48,3 \%$ \\
$>74$ & 15 & $51,7 \%$ \\
Jumlah & 29 & $100 \%$ \\
\hline
\end{tabular}

Sumber : Data primer

Berdasarkan tabel di atas dapat dilihat bahwa usia lansia di panti sosial tresna werdha budi pertiwi pada tahun 2015 sebagian besar berusia $>74$ tahun yaitu 14 lansia $(51,7 \%)$ dan sebagian kecil berusia $60-74$ tahun 14 orang $(23,8 \%)$.

Tabel 3. Distribusi Frekuensi Responden Berdasarkan Jenis Kelamin Pada Lansia Di Panti Sosial Tresna Werdha Budi Pertiwi

\begin{tabular}{lcc}
\hline Jenis Kelamin & f & \% \\
\hline Laki - laki & 0 & $0 \%$ \\
Perempuan & 29 & $100 \%$ \\
Jumlah & 29 & $100 \%$ \\
\hline
\end{tabular}

Sumber : Data Primer

Berdasarkan tabel di atas dapat dilihat bahwa jenis kelamin pada lansia di panti sosial tresna werdha budi pertiwi semuanya perempuan dengan jumlah 29 lansia(100\%).

Tabel 4. Distribusi Frekuensi Responden Berdasarkan Pendidikan Terakhir Pada Lansia Di Panti Sosial Tresna Werdha Budi Pertiwi

\begin{tabular}{lcc}
\hline $\begin{array}{l}\text { Pendidikan } \\
\text { Terakhir }\end{array}$ & $\mathbf{f}$ & $\boldsymbol{\%}$ \\
\hline Tidak Sekolah & 11 & $37,9 \%$ \\
SD & 11 & $37,9 \%$ \\
SMP & 4 & $13,8 \%$ \\
SMA & 2 & $6,9 \%$ \\
Perguruan & 1 & $3,4 \%$ \\
Tinggi & 29 & $100 \%$ \\
Jumlah &
\end{tabular}

Sumber : Data Primer

Berdasarkan tabel di atas dapat dilihat bahwa pendidikan terakhir pada lansia di panti sosial tresna werdha budi pertiwi adalah 11 lansia (37,9\%) tidak berpendidikan, 11 lansia $(37,9 \%)$ berpendidikan SD, 4 orang $(13,8 \%)$ Jurnal Pendidikan Keperawatan Indonesia 2(1) : 38-43 (2016) berpendidikan SMP, dan 2 orang $(3,4 \%)$ berpendidikan SMA, serta 1 orang $(3,4 \%)$ berpendidikan Perguruan Tinggi.

Lansia adalah proses alami yang tidak dapat dihindari. Semakin bertambahnya usia, fungsi tubuh pun mengalami kemunduran sehingga lansia lebih mudah terganggu kesehatanya, baik kesehatan fisik maupun kesehatan jiwa (Maryam dkk., 2008). Karena keadaan fisik yang banyak mengalami kemunduran sehingga membuat lansia kurang motivasi untuk berolah raga seperti senam lansia karena minimnya pengetahuan mengenai senam lansia.

Menurut data yang didapatkan lansia yang berpengetahuan cukup 14 orang $(48,3 \%)$, meskipun hal ini tidak terlalu jauh perbedaannya dengan tingkat pengetahuan baik dan kurang yang memperlihatkan sebagian responden berpengetahuan baik 14 orang $(48,3 \%)$ dikarenakan sudah dilakukan penyuluhan tentang senam lansia sebelumnya dan sebagian kecil responden berpengetahuan kurang 1 orang $(3,4 \%)$ ini disebabkan oleh beberapa faktor yaitu usia, pengalaman, dan pendidikan. Mengingat pada tabel di atas umur lansia menurut WHO didominasi 60-74 tahun 14 lansia $(48,3 \%)$ dan umur > 74 tahun ada 15 lansia $(51,7 \%)$ dimana menurut Notoatmodjo (2010) semakin cukup umur, tingkat kematangan seseorang akan lebih tinggi pada saat berpikir dan bekerja terutama pada usia lanjut. Pada usia tahap ini (>74 tahun) yaitu lanjut usia akhir, individu akan lebih berperan aktif dalam masyarakat dan kehidupan sosial, serta lebih banyak melakukan persiapan demi suksenya upaya menyesuaikan diri menuju usia tua.

Hal ini sesuai dengan yang dikemukakan oleh Notoatmodjo (2013) yang menyebutkan bahwa data hasil penelitian dipengaruhi oleh tingkat pengetahuan. Penelitian ini pun sejalan dengan penelitian Veronica, dkk (2011) didapatkan bahwa hasil penelitian menunjukkan bahwa tingkat pengetahuan 
lansia dalam kategori baik (54\%), cukup (6\%), dan kurang (40\%).

Pengetahuan lansia dapat dipengaruhi oleh berbagai faktor seperti budaya, kebiasaan, dan pengalaman hidup. Menurut Notoatmodjo (2010) pengalaman merupakan sumber pengetahuan, atau pengalaman itu merupakan suatu cara untuk memperoleh kebenaran pengetahuan. Salah satu faktor lain yang diungkapkan oleh Kuncoroningrat (1997, dalam Mubarak, 2008, hlm.145) yaitu pendidikan, yang menyebutkan bahwa semakin tinggi pendidikan seseorang semakin mudah menerima informasi sehingga semakin banyak pengetahuan yang dimiliki. Hal ini sejalan dengan hasil pendidikan terakhir lansia bisa mempengaruhi pengetahuan proses belajar, makin tinggi pendidikan seseorang, makin mudah orang tersebut untuk menerima informasi ini menurut notoatmodjo (2010), ini sejalan dengan penelitian yang dilakukan peneliti di panti sosial tresna werdha budi pertiwi sebagian besar lansia 11 lansia $(37,9 \%)$ tidak bersekolah, 11 lansia $37,9 \quad(37,9 \%)$ berpendidikan SD, 4 lansia $(13,8 \%)$ berpendidikan SMP, 2 lansia $(6,9 \%)$ berpendidikan SMA, dan 1 lansia $(3,4 \%)$ berpendidikan perguruan tinggi.

\section{SIMPULAN}

Gambaran pengetahuan lansia mengenai senam lansia di panti sosial tresna werdha budi pertiwi diperoleh kategori tertinggi yaitu kategori baik 14 lansia, kategori cukup 14 lansia dan untuk pengetahuan dengan kategori kurang 1 lansia.

\section{DAFTAR PUSTAKA}

Arikunto, S. 2010. Prosedur Penelitian Suatu Pendekatan Praktek. Jakarta: Rineka Cipta.

Caesar, A. (2012). Validitas dan reliabilitas. (online). Tersedia di: http://arihdyacaesar.wordpress.com/20 12/01/13/validitas-dan-reliabilitas/. Diakses : 15 Mei 2015.
Hidayat, A. A. (2011). Metodologi penelitian keperawatan dan teknik analisis data. Jakarta : Salemba Medika.

Jamilah,W (2013) "Pengetahuan Dan Sikap Lansia Tentang Senam Lansia Di Desa Mompang Kecamatan Berumun Kabupatn Padang Lawas" hlm 1

Maryam RS, Ekasari, MF, dkk. (2008). Mengenal Usia Lanjut dan Perawatannya. Jakarta: Salemba Medika

Notoatmodjo. (2013). Metodologi Penelitian Kesehatan. Jakarta: Rineka Cipta.

Notoatmodjo. (2007). Promosi Kesehatan \& Ilmu Perilaku. Jakarta: Rineka Cipta

Nursalam. (2011). Konsep dan Penerapan Metodologi Penelitian Ilmu Keperawatan. Edisi ke-2. Jakarta : Salemba Medika.

RISKESDAS. (2013). Laporan Nasional 2013. Riyanto, A. (2011). Pengolahan dan Analisis Data Kesehatan. Yogyakarta: Nuha Medika. 